\title{
ANALYSIS ON THE ROAD TRANSPORTATION NETWORKS OF THE AMHARA REGION, ETHIOPIA
}

\author{
Tsetadirgachew Legesse ${ }^{1}$ \\ ${ }^{1}$ Department of Geography and Environmental Studies, Adama Science and Technology University, \\ Adama 1888, Ethiopia
}

Received 4 November 2014; accepted 4 April 2016

\begin{abstract}
The Amhara National Regional State is lying between the Abay and Tekeze rivers with vast territory, endowed with varied climatic regions and different kinds of natural recourses. It is one of the areas of earliest settlement in Ethiopia as a result of which has been experiencing high deterioration of natural resources. The rugged and steep escarpments and the frequently incised topography are making the construction of road transportation very difficult and expensive in financial terms. Moreover, landslides and severely eroded gullies in regions of heavy precipitations have exacerbated the problems to enhance the road network of the area as a result of which it remained far from adequacy for the population of the region. Even today the transport map of the region is most impressive by it bareness.

Generally, the overall results of this study indicate that the road network in the Amhara National Regional State is with single connection tree like shape with few extended arms, with the value of Beta index less than 1, Cyclomatic number equals 0, Gamma index between 0-0.42, Alpha index ranging between 0-0.6. These results show that most of the areas in Amhara region are inaccessible and need a long distance travel to access the nearest road. Based on these empirical findings and the reviewed literature, the researcher would like to recommend that the construction of more road networks is imperative in Amhara region taking into account the socio-economic importance of the areas to be connected to the main road system of the country.
\end{abstract}

Keywords: transportation, road network, connectivity, centrality, transport indexes, Amhara region, Ethiopia.

\section{Introduction}

Transportation is the most important and vital means to spur development in any place on Earth. As one of the ancient state on the surface of our planet the Ethiopia is not benefited much in connecting its area to the remaining part of the world. Most areas remained unconnected to each other (EMA, 1988). Poor transportation development in Ethiopia has impacted negatively on the socio-economic growth of the country (Mesfin, 1972). Similarly, the transportation sector in Amhara region is found at its rudimentary stage. Most of the people and goods move by use of human and/or animal muscles.

However, no profound research has been to tell the connectivity and accessibility level of places in the region though it is meaningful to say the region has low connectivity and

${ }^{1}$ Corresponding author: T.legesse@astu.edu.et 
accessibility level as compared to international levels and indices. No doubt, this affects the life condition of most rural population and even the urbanites at large. These people may suffer from lack of access to most public facilities like education, market places and health facilities. This indicates that the improvement of modes of transport has valuable contribution to economic, social and political development. In reality the Amhara region is very far from this fact. Generally, road network plays valid role in bringing about sustainable growth as noted in Pradhan (2010).

People living in such isolated areas have remained price-recipients rather than pricemakers for their goods. Their level of access to public facilities has remained minimal and/or non-existent since antiquities. Worku

(2011a) has stated that rural accessibility still remain far from desire target level that the region need to have. Off road motorized transport is not viable in most areas because of the difficult terrain. The general situation of Amhara region, the pivot of this study, is not different form this general picture of Ethiopia. According to Worku (2011b) rural accessibility still remains far from the desired target level that the country or the region need to have. Admasu (2013) indicated that transportation infrastructure in the country has been neglected for decay and responsible for low industrial development in the country. In general speaking, road transportation is the recent phenomena in Ethiopia especially in the northwestern part of Ethiopia where the nucleus of the study (Amhara region) is located.

The overriding objective of this research was to analyze the road network in Amhara region, northwest Ethiopia. More specifically, the study is aspired to:
- outline the geographic evolution of road transport network in Amhara region;

- identify sequences or stages of evolution in the development of road transport network of the region;

- examine the spatial and structural characteristics of the Amhara region;

- identify areas of lead and lag in road transport network in Amhara region;

- give suggestion, recommendation about the improvement of road transport.

\section{Materials and Methods}

Different secondary data were gathered and analyzed in order to achieve the objectives of this study. Temporally sequential maps, documents and different related research works were consulted. In order to get the data adequately analyzed and presented, different analytical techniques and indices were employed. Firstly, the existing topological maps were digitization by using ArcGIS tools. The spatial extent of areas and lengths of each road segments were computed from the digitized by using ArcGIS techniques. Similarly, ArcGIS tools were used to exactly identify and quantify the nodes and arcs of roads in the region. Then the nodes and arcs were carefully counted to compute the Beta Index, the Cyclomatic Number, the Gamma Index, the Alpha Index, Shimbel Index and the road density of the region. The result of these data is processed and analyzed qualitatively by using SPSS and ArcGIS softwares. Different tables and graphs have been prepared to show connectivity level of the road transport in the region. Comparative analysis was made among places in the region to find out their levels of connectivity, centrality and density. The quantitative data in tables and figures have been followed by interpretations and discussions to give a clarity and simplicity of the research report. 


\section{Review of Related Literature}

Many scholars have given their different ideas about transport and its nature. Brain (1988) described transportation as a measure of interaction between areas and considers it to be the basic part of geography. The degree of interaction among areas can be reflected in the extent of development of transportation facilities. Robinson and Bamford (1978) states that transport is demanded because of the need to get quickly and safely from home to work and in order to move goods from factories or depot to the whole seller and retailers.

World Bank Project Appraisal Document (2003) describes transportation as: "It is factor that helps to promote on over all development for a give nation or areas by facilitating agricultural production and by avoiding inequality between regions through exchange of goods and services as well as ideas.”

The absence of transportation facilities leads in to isolation, which in turn reduces economic and social progress and it delays economic integration (Taaffe and Gauthier, 1973). This situation is common in the rural areas of the Amhara region. However, the spatial distribution of distribution of roods in the Amhara region remained inequitably distributed. It highly varies both in length and density from place to place throughout the country.

The present network growth in the Amhara region was a function of both a continuous process of spatial diffusion and irregular or sporadic process influenced by much specific economic social or political force.
The network has reached to $9160 \mathrm{~km}$ in 1973. On average, the network has been growing at a rate of $2.05 \%$ per annum over the period 1951-1973. Between 1974-1991 the stock road increased to $19017 \mathrm{~km}$ with a growth rate of $6.2 \%$ per annum. The road network has reached $46812 \mathrm{~km}$ in 2009 with an average annual growth rate of $9.35 \%$. Over the period 1991 to $2009,28731 \mathrm{~km}$ of new road network was constructed. Road constructions are become common phenomena in all rural areas and regional states in Ethiopia. Still large areas bereft of modern transport links and areas plagued by inaccessibility due to under development and lack of proper maintenances. Recently replacement of gravel roads by asphalt roads has been taking a lead than the case in any history of the region (Wondemu and Weiss, 2012; World Bank Project Appraisal Document, 2003).

\section{Background and the Development of the Region}

The Amhara National Regional State is extended between latitude from $9^{\circ}$ to $13^{\circ} 45^{\prime}$ $\mathrm{N}$ and longitude from $36^{\circ}$ to $40^{\circ} 30^{\prime} \mathrm{E}$ (Fig. 1). The total area of the regions estimated at $170152 \mathrm{~km}$, which is about one sixth of the country's total area. The topography of the region is very variable ranging from lowlands around $+1,000 \mathrm{msl}$ up to the bottom of the eastern escarpment and in the valley to the top of Ras Dejen at +4,610 msl (EMA, 1988). Generally lowland areas experience relatively hotter temperature conditions as compared to the highlands. Where the altitude ranges from +600 to $+1400 \mathrm{msl}$, the mean annual temperature range is $210-270^{\circ} \mathrm{C}$, while in the cold to very cold moist zone, where the altitude ranges from $+2800-+4200 \mathrm{msl}$, the mean annual temperature varies from 7.50- 
$160^{\circ} \mathrm{C}$ (Desta et al., 2000). The Amhara region is characterized by excellent human habitat before recent degradation (Hurni, 1988; Richard, 1973).

Still we may have 23740000 human population and 78936968 livestock which has strong impact on the environment of the given area. Generally the Amhara region is characterized by series of short, connected highway lines which have limited number of circuits in creating low economic coordination and return to investment of firm (Fig. 2). In reality, people remain isolated in area with no or less communication.

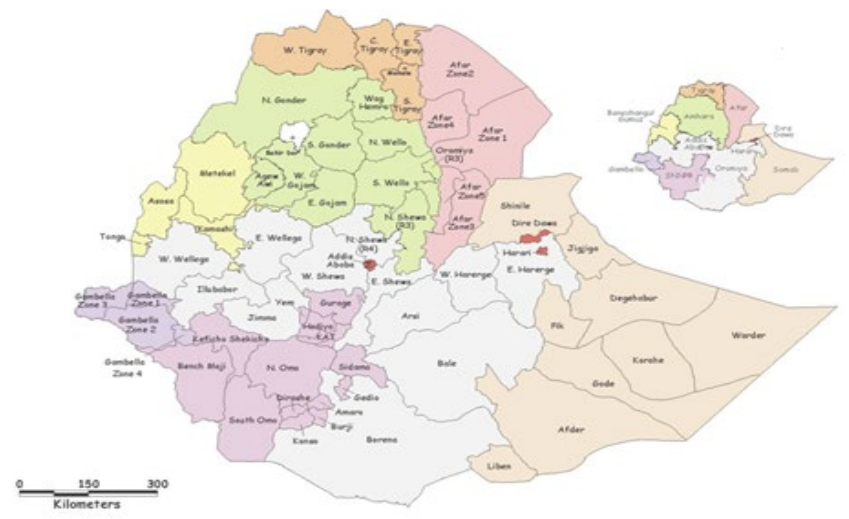

Fig. 1.

Administrative Regions and Zones of Ethiopia

Source: Amhara Regional State (2013)

\section{Results and Discussion}

Here, the topological road network analysis of the Amhara region is computed based on both-qualitative and quantitative ways. In analyzing and classifying the Amhara region transportation network, the relative positions of nodes and contiguity of routes and points are systematically analyzed (Fig. 2). Community roads were not included in computation since they are not permanently used or seasonally interrupted by heavy rainfall. 


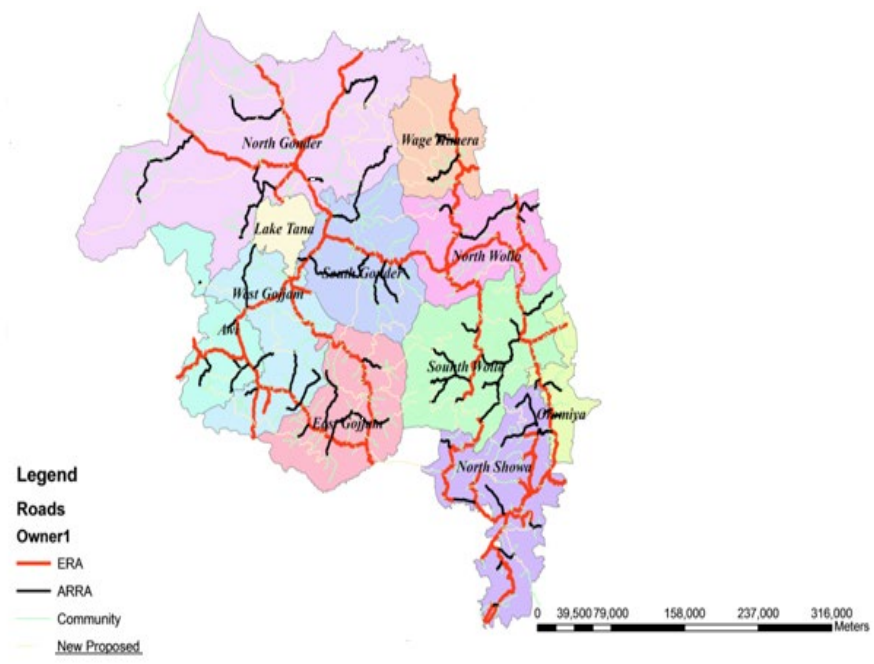

Fig. 2.

Road Network of the Amhara Region

Source: Amhara Regional State (2013)

The ways in which a number of edges and arcs are interconnected were measured by several indexes developed in a graph (Alemseged, 1986) which will be described as subsequently in the following ways.

\subsection{Beta Index}

Table 1 indicates Beta value of different zones of the Amhara region. Areas like south Gonder and Wollo are having the Beta value of one; while Gojjam and north Gonder are having Beta values less than one. The former group of areas is having fewer edges than the second groups of areas. All zones (areas) are characterized with a least -net effort transport system with a tree like structure with less enclosed areas. No areas of greater complexity, which includes higher than one.

\section{Table 1}

The Relationship between Total Number of Arches (A) and Nodes (N)

\begin{tabular}{|c|c|c|c|}
\hline Zones & No of Arch & No of Nodes & $\begin{array}{l}\text { Beta Index (Arch/Node }) \\
\beta=\frac{\sum e}{\sum v}\end{array}$ \\
\hline West Gojjam \& Awi & 22 & 23 & 0.95652 \\
\hline East Gojjam & 14 & 15 & 0.9333 \\
\hline North Gonder & 20 & 21 & 0.9523 \\
\hline South Gonder & 28 & 28 & 1 \\
\hline North Wollo \& Wagmira & 14 & 14 & 1 \\
\hline South Wollo \& Oromia & 28 & 28 & 1 \\
\hline North Shewa & 22 & 23 & 0.9565 \\
\hline
\end{tabular}

Source: Computed from the Net Work Map of the Amhara Region

\section{ijtte 216}




\subsection{Cyclomatic Number}

Table 2

Cyclomatic Number for the Amhara Region

\begin{tabular}{|l|l|l|l|l|}
\hline Zones & No of Arch & No of Node & Sub Graph & $\begin{array}{l}\text { Cyclomatic Number } \\
\boldsymbol{\mu}=\mathbf{e}-\boldsymbol{v}+\mathbf{p}\end{array}$ \\
\hline West Gojjam \& Awi & 22 & 23 & 1 & 0 \\
\hline East Gojjam & 14 & 15 & 1 & 0 \\
\hline North Gonder & 20 & 21 & 1 & 0 \\
\hline South Gonder & 28 & 28 & 1 & 1 \\
\hline North Wollo \& Wagmira & 14 & 14 & 1 & 1 \\
\hline South Wollo & 28 & 28 & 1 & 1 \\
\hline North Shewa & 22 & 23 & 1 & 0 \\
\hline
\end{tabular}

Source: Computed from the Net Work Map of the Amhara Region

The results presented in Table 2 are indicating that areas like Gojjam (east and west), Gonder are having the Cyclomatic number values of zero, while areas like south Gonder and south and north Wollo is having the Cyclomatic values of one. These results can explain how the regional transport development failed to from the closer enclosed areas. Even the existed enclosed areas are large in area, and not able to bring close interaction of the population and the economy. This in return manifested a least - net - effort transport system with the tree like structure, which resulted in the lack of territorial interdependence and weak tree like structure, which resulted in the lack of territorial interdependence and weak linkage productive centers.

\subsection{Gamma Index}

Table 3

Gamma Index for the Amhara Region

\begin{tabular}{|l|l|l|l|}
\hline Zones & Actual Edges (e) & $\begin{array}{l}\text { Maximum Edges } \\
\mathbf{3}(\boldsymbol{v}-\mathbf{2})\end{array}$ & $\begin{array}{l}\text { Gamma Index } \\
\boldsymbol{\gamma}\end{array}$ \\
\hline West Gojjam \& Awi & 22 & 66 & $\mathbf{3}(\boldsymbol{v}-\mathbf{2})$ \\
\hline East Gojjam & 14 & 43 & 0.33 \\
\hline North Gonder & 20 & 37 & 0.33 \\
\hline South Gonder & 28 & 72 & 0.540 \\
\hline North Wollo \& Wagmira & 14 & 36 & 0.388 \\
\hline South Wollo & 28 & 63 & 0.388 \\
\hline North Shewa & 22 & 63 & 0.444 \\
\hline
\end{tabular}

Source: Computed from the Net Work Map of the Amhara Region

For a completely connected network the index always lies between 0 and 1 . As indicated in Table 3, the Gamma index for
Amhara region lies between 0.33 to 0.44 while areas like west and east Gojjam, northern and southern Gonder, north and 
south Wollo and north Shewa are having $0.33,0.33,0.54,0.38,0.44$ and 0.349 respectively. Relatively highest Gamma index is calculated to north Gonder which is located in the northern part of the region.
Over all from the result of Table 3, it is understood that the whole network in the Amhara region is less structured and with poor socio-economic development which manifested with high poverty index.

\subsection{Alpha Index}

\section{Table 4}

Alpha Index for the Amhara Region

\begin{tabular}{|l|l|l|l|}
\hline Zones & $\begin{array}{l}\text { Actual Circuit } \\
(\boldsymbol{a}-\boldsymbol{n}+\boldsymbol{p})\end{array}$ & $\begin{array}{l}\text { Maximum Circuit } \\
\mathbf{2 n - 5}\end{array}$ & $\boldsymbol{\alpha}=\frac{\mathbf{u}}{\mathbf{2 v - 5}}$ \\
\hline West Gojjam \& Awi & $22-23+1$ & $2(23-5)$ & $0 / 36=0$ \\
\hline East Gojjam & $14-15+1$ & $2(15-5)$ & $0 / 20=0$ \\
\hline North Gonder & $20-21+1$ & $2(21-5)$ & $0 / 32=0$ \\
\hline South Gonder & $28-28+1$ & $2(28-5)$ & $1 / 46=0.2$ \\
\hline North Wollo \& Wagmira & $14-14+1$ & $2(14-5)$ & $1 / 18=0.06$ \\
\hline South Wollo & $28-28+1$ & $2(28-5)$ & $1 / 46=0.02$ \\
\hline North Shewa & $22-23+1$ & $2(23-8)$ & $1 / 36=0.022$ \\
\hline
\end{tabular}

Source: Computed from the Net Work Map of the Amhara Region

Table 4 is indicating the Alpha index for the Amhara region is between 0 to 0.06 . All areas in the given region are having the Alpha values closer to zero or zero. This shows the area is having the lowest possible numbers of arcs and the minimum degree of connectivity.

\subsection{Centrality}

In order to know the Centrality of the study area the König number, Associated number and Shimbel index were used and the following results were recorded (Table 5).

\section{Table 5}

Level of Accessibility in the Amhara Region

\begin{tabular}{|l|l|l|l|l|}
\hline \multirow{2}{*}{ Zones } & \multicolumn{4}{|l|}{ Accessibility } \\
\cline { 2 - 5 } & Least Accessible & Total No of Arc & Most Accessible & Total No of Arc \\
\hline West Gojjam \& Awi & Adet, Tis Abay & 147 & Injibara & 64 \\
\hline East Gojjam & Motta & 34 & Bichea & 4 \\
\hline North Gonder & Adiarkay & 116 & Azezo & 37 \\
\hline South Gonder & Zabit & 43 & Debretabor & 23 \\
\hline North Wollo \& Wagmira & Debexabit & 61 & Wolideya & 32 \\
\hline South Wollo & Bora & 53 & Desse & 20 \\
\hline North Shewa & Alyoambo & 58 & Debrebrhan & 2 \\
\hline
\end{tabular}

Source: Computed from the Net Work Map of the Amhara Region

Table 5 shows the result of most central places like Injibara (west Gojjma), Bichena (east Gojjam), Woldeya (north Wollo),
Desse (south Wollo) and Debre Birhan in north Shewa. Most of all these places are still serving as political and culture centers 
of their respective zones except Bichena, Injibara and Azezo. The Administrative centers of Gojjam and Gonder are not in a more central place like other places. This can create difficulties for the population to reach their administrative centers when need arises. As the result poor administration serves and weak administration control over the population. Distance from administrative center has negative impact in rural production availability in the relatively dense area of the center. While Tis Abay and Adet (west Gojjam), Motta (east Gojjam), Adiarkay (north Gonder), Zabit (south
Gonder), Debrezabit (north Wollo), Bora (south Wollo) and Alyambo in north Shewa are called the least accessible areas in nodes in their respective areas (zones). Practically these areas are called inaccessible areas in their respective zones and are defined as remote and unattractive places in the region. The road density of the region is 0.3496 per $\mathrm{m}$. This can be defined as one of the lowest density than anywhere in the continent. Perhaps three fourth of farms living in the rural areas has to travel or walk more than six hours to reach the nearest weathered road (Worku, 2011b).

Table 6

Road Density and Availability in Terms of Population

\begin{tabular}{|l|l|l|l|l|l|}
\hline & $\begin{array}{l}\text { Length } \\
\text { of Road }\end{array}$ & $\begin{array}{l}\text { Area } \\
\mathbf{k m}^{2}\end{array}$ & $\begin{array}{l}\text { Density Length } \\
\text { of Population }\end{array}$ & $\begin{array}{l}\text { Total } \\
\text { Population }\end{array}$ & $\begin{array}{l}\text { Roads in Terms of Population } \\
\text { Lengths/Population }\end{array}$ \\
\hline West Gojjam \& Awi & 379.5 & 22500 & 0.01686 & 259251 & 0.0001463 \\
\hline East Gojjam & 234 & 23000 & 0.01017 & 1700331 & 0.0001376 \\
\hline North Gonder & 423 & 58800 & 0.00719 & 2088297 & 0.0002025 \\
\hline South Gonder & 320 & 1707 & 0.01876 & 1788732 & 0.0001788 \\
\hline North Wollo \& Wagmira & 727.5 & 23000 & 0.03154 & 1535932 & 0.0004736 \\
\hline South Wollo & 589.5 & 31500 & 0.01853 & 25951 & 0.0002273 \\
\hline North Shewa & 410.2 & 44000 & 0.00932 & 1560916 & 0.0002627 \\
\hline
\end{tabular}

Source: Computed from the Net Work Map of the Amhara Region

Table 6 indicates that the road density of the given region is ranging between 0.0142 0.6627 for the whole region. The tendency of density decline is observed from zones of west Gojjam to north Gonder and north Shewa. These may be due to the decreased population density and increased central interaction.

The relationship between population and length of roads in the study area is also indicating, nearly no value. It also shows high usability or pressure on the existing roads. Zonal disparities can, to some extent, be portrayed when the density of road type and accompanying length is considered. Zonal road density, therefore, lies between 0.0001436-0.000476. It indicates that there is no or little modern mode of transportation. Thus the population dependent on traditional methods of transportation ( $\mathrm{Ox}$, mule donkeys, and horses) may still remain beyond the effective reach of modern and more efficient carriers.

\section{Conclusion and Recommendations}

The Beta values of all zones are ranging between 0.9333-0.956. It is below the national average (i.e. $<1.01$ ). The results 
are much closer to each other. It shows that no significant difference among different zones in the region in terms of road transport development.

The Gamma index for the whole zones is less than one except Wello. Most zones are less structural and with poor socio-economic development which Wollo is more or less structured zone. The value of Alpha index of the region is between 0-6\%. It shows that the area is having the lowest possible numbers of arcs and the minimum degree of connectivity. These results giving us enough evidence that road transportation system like tree throughout the successive periods in the region. These low connectivity values can highly affect regional specialization of the region and high pressure on the existing road.

The most central places in the region are Injibara (west Gojjam), Bichena (east Gojjam), Woldeya (north Wollo), Desse (south Wollo), Debrebrian (north Shewa), except Bichena and Azezo. Most of them are acting as political and cultural centers to their respective zone. The selection of central place as a zonal centers are more or less appropriate for the most places.

The road density of the region is one of the lowest in the Ethiopian territory. Zonal disparities can be observed easily. These low results can show that there is high usability on the existing roads. Free and easily movements of agricultural products and people cannot be expected. Road density is relatively higher in high densely populated and in rich agricultural areas. Good roads and well developed road systems are scarce and large. Areas of the region is highly neglected and remained isolated for a long period of time. High cost of transport and weak competition exerted strange influence on the development and patterns of transport in that region.

The low level of transport development results in the lack of territorial interdependence and weak linkage among productive centers. An effective tool of regional development policy must be taken by the government in this sector:

- To keep pace with the influence of modernization it is therefore, necessary to fill the mobility gap by the expansion of other mode of transport.

- The participation of the majority of the rural population and NGO should be encouraged and well-come in order to enhance the connectivity of the area.

- Seasonally affected roads should be replaced by all weathered roads.

- Regional specialization is highly recommended.

- Large mechanized agricultural and modern industrial areas should be wellcome in the region in order to improve the transport system in the region.

- Creation of new urban areas should be encouraged in order to enhance the numbers of nodes in the given region.

- More new roads should be constructed in a more planned way in order to create more enclosed areas which can promote regional specialization.

\section{Acknowledgments}

The author profound thanks and gratitude to Mesay Mlugeta for his encouragement and support. 


\section{References}

Admasu, S. 2013. Road Infrastructure and Enterprise Dynamics in Ethiopia. Williamsburg, The College of William and Mary, USA.

Alemseged, G. 1986. Geography of Transport and Development. Addis Ababa University, Bahirdar Teachers College, Bahirdar.

Brain, H. 1988. Modern Transport Geography. Edition 2, Wiley.

EMA. 1988. National Atlas of Ethiopia. Addis Ababa.

Hurni, H. 1988. Degradation and Conservation of Soil Resources in Ethiopia Highlands. Presented at the First International Workshop on African Mountains and Highlands: Ethiopia Mountains Research and Development, 8(2-3): 123-130.

Desta, L.; Kassie, M.; Benin, S.; Pender, J. 2000. Land Degradation and Strategies for Sustainable Development in Ethiopia Highlands, Amhara Region, ILRI and Nairobi, Kenya.

Mesfin, W. 1972. An Introduction of Ethiopian Geography. Addis Ababa, Ethiopia.

Pradhan, R.P. 2010. Transportation Infrastructure, Energy, Consumption and Economic Growth Triangle in India: Cointegration and Causality Analysis, Journal of Sustainable Development, 3(2): 167-173.
Richard, P. 1973. The Economic History of Ethiopia. Addis Ababa, Ethiopia.

Robinson, H.; Bamford, C.G. 1978. Geography of Transport. MacDonald and Evans.

Taaffe, E.; Gauthier. H. 1973. Geography of Transportation. Prentice-Hall, New Jersey.

Wondemu, K.A.; Weiss, J. 2012. Rural Roads and Development: Evidence from Ethiopia, European Journal of Transport and Infrastructure Research, 12(4): 417-439.

Worku, I. 2011a. Road Sector Development and Economic Growth in Ethiopia. EDRI Working Paper 4. Addis Ababa, Ethiopia.

Worku, I. 2011b. Road Sector Development, Stock of Achievements, Impact on Overall and Sectoral Economic Growth. Ethiopia Development Research Institute (CEDRI), Addis Ababa, Ethiopia.

World Bank Project Appraisal Document. 2003. Ethiopia - Second Road Sector Development Program Project World Bank, Chicago. 